\title{
OBTAINING THE EQUATIONS OF MOTION OF A MECHANICAL BODY THROUGH ANALYTICAL METHODS
}

\author{
Armandt Erasmus ${ }^{1}$ \\ ${ }^{1}$ Affiliation not available
}

October 4, 2021

\begin{abstract}
The aim of this paper is to obtain the equations of motion in n-dimensional space for the case where no external forces act on a mechanical system using analytical methods. One such method is known as Lagrangian Mechanics. Lagrangian Mechanics is founded on the principle of least action which states that the spontaneous change from one configuration to another of a dynamical system has a minimum action value if the law of conservation of energy holds.
\end{abstract}

\section{Hosted file}

OBTAINING THE EQUATIONS OF MOTION OF A MECHANICAL BODY THROUGH ANALYTICAL METHODS.pdf available at https://authorea.com/users/381445/articles/540218-obtaining-the-equations-ofmotion-of-a-mechanical-body-through-analytical-methods 